\title{
Gender Relations in the Armed Forces: Does the Draft Make a Difference?
}

\author{
Helena Carreiras*
}

\begin{abstract}
This paper addresses the way how gender relations in the military are affected by personnel accession policies, namely the existence or absence of the draft. After reviewing the weight of military variables within theoretical models of factors that affect women's military roles, the paper proceeds with an inquiry into results of empirical studies that have aimed at evaluating this relationship. It ends with concluding remarks on the effects of changing representation patterns and of organisational policies on gender integration.
\end{abstract}

Keywords: Gender relations, armed forces, draft, military accession policies

Geschlechterbeziehungen, Streitkräfte, Wehrpflicht, militärische Rekrutierungsspolitik

\section{Introduction}

$\mathrm{F}$ rom the mid 1970s, the historical pattern of women's exclusion from regular military participation has been dramatically challenged. Contrasting with the exceptionality of their prior involvement in warfare, women have started to be admitted in the armed forces in peacetime and with full military status. By the beginning of the 21st century, most Western democratic countries had admitted and increased the number of women in their armed forces. Although restrictions persisted, many were lifted; women were progressively allowed to enter military academies and given access to a wider variety of positions and functions; gender awareness grew within military structures and integration policies were designed and implemented (Harries-Jenkins, 1980; Goldman, 1982; Reynaud, 1988; Holm, 1993; Carreiras, 2006).

Two main types of influence have been identified to explain the various rhythms and characteristics of female military recruitment, as well as policy orientations regarding gender integration in the armed forces. On the one hand, there are factors stemming from global social and political change: democratic pressures towards more egalitarian gender values and transformation in women's social and political participation, such as their entry in the labor market and change in family structures; on the other hand -and probably wielding a more direct influence-, there are transformations within military organizations deriving from major shifts in international relations as well as from technological change: the inversion of the ratio between combat and support functions, organizational fragmentation and occupational specialization, the end of mass armies and the development of all-volunteer forces, increasing professionalization and size reduction. All these have determined the need for more qualified personnel and underlined the dependence of the military on the global society (Moskos and Wood, 1988; Moskos, Williams and Segal, 2000).

There is however, strong variation between countries. While some have integrated women, granting them real (and not only formal) access to a wide range of occupations, others keep women in little more than symbolic positions (Segal, 1995; Simon, 2001; Winslow and Dunn, 2002). Such variation ranges from a very limited numerical presence, rank limitations, segregated training and severe functional restrictions to relatively open career patterns, fully integrated training and access to combat roles. In order to explain this variation, sociologists have put forward complex interpretative models, including social, political, cultural and organizational factors that together are supposed to explain differences between countries. Although the relative weight of these factors is supposed to vary, depending on context, all of these proposals underline the direct impact of military organisational variables, considered to be powerful determinants of women's military roles.

But how exactly does the organisational format of the armed forces affect gender relations? What has research shown about this? To what extent does the existence or absence of the draft make a difference?

The objective of this paper is to address the way how gender relations in the military are affected by personnel accession policies, namely the existence or absence of the draft. Therefore, it isolates military organisational factors for analytical purposes. After reviewing the weight of these variables within theoretical models of factors affecting women's military roles, the paper proceeds with an inquiry into results of empirical studies that have aimed at evaluating that relationship. It ends with concluding remarks on the effects changing representation patterns and of organisational policies on gender integration.

\footnotetext{
* Helena Carreiras holds a PhD in Social and Political Sciences from the European University Institute in Florence. She is an assistant professor at ISCTEUniversity Institute of Lisbon, and senior researcher at CIES-IUL. Since 2010 she has been deputy director of the National Defence Institute in Lisbon. This article has been peer-reviewed.
} 


\section{Military Organizational Format and Gender Integration in the Armed Forces: Theoretical Assumptions}

The extent to which women have participated in the armed forces, cross-nationally and throughout time, has been considered to depend on a wide set of factors, both internal and external to the military organization. Analytical models have included the impact of social, cultural, political and organizational variables to explain observed patterns of female military participation (Segal, 1995; Kuemmel, 2002; Iskra et al., 2002; Carreiras, 2006). The relative impact and interaction of these factors is associated with varying historical conditions, and if it is relatively easy to list them, it is more difficult to assess how they interact and how, under specific circumstances, some acquire more salience or how opposite tendencies operate. In one of the first essays aimed at explicit theory-building in this field, Segal outlined a systematic theory of the conditions under which women's military roles may expand or contract, assessing, to a certain extent, the relative and combined effects of those variables (Segal 1995).

According to her, increases in women's participation are likely to happen when military missions and values are perceived as being more compatible with women's service, when changes in women's social participation make them more suited and willing to perform military roles and/or when threats to national security are so serious as to require the participation of all citizens. Remarkable effects may be witnessed when military needs and gender values are at odds with each other.

In this framework, military variables are considered to be of overriding importance. Here, the national security situation -level of threat and nature of military missions-, technological changes, and various aspects related to force structure and military accession policies are highlighted.

As far as the national security situation is concerned, the author sustains that when there are shortages of men, during times of national emergency, most nations increase women's military roles. Historical evidence shows that many nations have drafted women in wartime and their participation in revolutionary movements is a common pattern. Thus, at the high end of the threat to the society, women's military roles seem to increase. However, evidence also seems to support the hypothesis that in societies with low threats to national security, but with cultural values supporting gender equality, women's military participation increases. On the contrary, medium threat ${ }^{1}$ seems to be associated with low participation of women.

The nature of military missions is also considered to influence the extent of women's participation. Segal hypothesizes that "the greater the relative importance of actual war fighting (especially ground combat) the less the participation of women" arguing that, on the contrary, the more the armed forces are involved in peacekeeping missions or operations that

1 Medium threat is defined as "the situation in which the society is not threatened with imminent extinction or invasion by superior military forces, but there is a moderate to high probability of military action on its soil in the near future" (Segal, 1995: 762). resemble domestic police functions, the greater is expected to be women's engagement (Segal, 1995: 762).

Although with a much less linear relation to women's roles, military technology is another important variable in the model, since technological changes such as the miniaturization of weapons, the development of air power and nuclear technology, have had a fundamental impact on the way war is conducted and on the characteristics of military jobs. These developments have enormously amplified the share of support jobs and, since women's participation is expected to be negatively affected by the proportion of combat jobs, they have - if indirectly enabled the participation of women in the armed forces.

The likelihood of international deployments presents an additional factor. While warfare at home can count on civilian infrastructures, engagements away from home require the deployment of support personnel. Segal has argued that as long as women remain mainly occupied in support functions, their number and roles can be expected to rise as the number and proportion of personnel with primarily support functions rises (Segal, 1995: 764). The impact of this variable on women's roles may however vary depending on which positions are open to them and which ones they actually fill.

Finally, and most relevant with regard to the objectives of this paper, various aspects related to force structure and military accession policies are also considered to have a significant impact on women's participation. For instance, as long as support functions are concentrated on the reserves, women will be more strongly represented in the reserves than in active duty forces. Consequently, the greater the reliance on reservists for wartime mobilization, the greater will be the participation of women in such mobilization. Furthermore, the de-legitimation of conscription and the increase in all-volunteer forces seem to be positively associated with the growing number of women in the armed forces. Based on historical evidence, Segal suggests that "women's military participation tends to increase under voluntary accession systems (as well as when social change is in the direction of gender equality)" (Segal, 1995: 765).

In the same vein, other researchers have strongly argued that nations considering a transition from conscription to a volunteer system tend to include plans to expand women's military participation. This has been shown in a study about the end of the mass-armies in the West, conducted by Haltiner (1998), which emphasized the importance of the Women's Ratio (the percentage of women compared with the total armed force), considered to be 'an excellent indicator of the army format'. Results of this research pointed to a general negative correlation between the degree of women's participation and the mass-army format of the armed forces: "the higher the WR, the lower is the mass army format of a force and the higher the degree of organizational role differentiation and specialization" (Haltiner, 1998: 54). Consequently, the author hypothesizes that "the degree of women's participation (...) will only substantially increase if conscription is abolished and the personnel will have to be recruited entirely on the labor market" (Haltiner, 1998: 60). According to this perspective, the existence of compulsory personnel for the military is the largest obstacle to an increase of the Women's Ratio. 
In sum, as far as military variables are concerned, the prediction is that the level of women's military participation is positively associated with technologically advanced militaries, allvolunteer forces, situations of high or low threat to national security, greater proportion of support functions and greater reliance on reserves for wartime mobilization. Inversely, medium threat scenarios, low technological development, conscript systems of military service and high combat to support ratios are expected to correlate negatively with women's participation.

\section{Military Organizational Format and Gender Integration in the Armed Forces: Empirical Findings}

All the above proposals have mainly focused on quantitative variables, namely the level of representation of women in the overall structure and across occupational areas. The question that can be raised here is the following: are there reasons to suppose that the proportion of women -the factor which is being considered to be a major consequence of the move to an all-volunteer force- makes any difference with regard to the experience of gender integration or gender relations in the military? Drawing on previous theoretical assumptions and empirical findings, the author explored this relationship through a comparative research on gender integration policies in the armed forces of NATO countries, providing empirical evidence concerning this universe (Carreiras, 2006).

A first step in this work was to address the relationship between organizational format and the representation of women.

The conscript ratio (CR - percentage of conscripts in total active force) was selected to measure the organizational format of the military in the various countries ${ }^{2}$. According to the theoretical proposals described above, the presumption is that the higher the CR of a military force, the lower is the representation of women and their role differentiation. On the contrary, the lower the $\mathrm{CR}$, the higher is expected to be the percentage of women and the less segregated their occupational distribution.

2 Even if this indicator might be considered a week proxy for the measurement of the mass-army character of a force, it has nevertheless been identified for operational reasons as one of the best indicators available, especially in that it avoids dichotomizing between conscript and volunteer systems. Researchers have noted that the armed forces have become smaller in size, technically and structurally much more differentiated, and increasingly reliant on volunteer personnel, regardless of whether conscription still exists or not. Due to the ongoing transformation trends as well as a large variety of unique developments and special national cases, "it makes little sense to dichotomize conscript systems and all volunteer systems as is done often in military sociology" (Haltiner, 1998: 50).
Results have shown that there was a negative correlation between the weight of conscripts in the total active force and the representation of women in the ranks. This seemed to confirm general research findings in this area that relate the percentage of women and the organizational format: the higher the mass-army format of a force, the lower is the representation of women (Figure 1).

Figure 1: Plot of countries' rankings: conscript ratio and percentage of women in the armed forces $(2000)^{1}$

Countries include: B - Belgium; C - Canada; CR - Czech Republic; Dk - Denmark; F - France; G Germany; Gr -Greece; H - Hungary; I- Italy; L - Luxembourg; NL- The Netherlands; N - Norway; Pl Poland; P - Portugal; S - Spain; T - Turkey; UK - United Kingdom; USA - United States

Figure 2 shows that the representation of women was higher in countries that had voluntary systems of military service or considered transition from conscript to all-volunteer forces and faced actual or potential recruitment shortages. Inversely, countries based on conscript military systems and no recruitment difficulties tended to have the lowest representation of women. On the basis of this identified relationship it was thus possible to reconfirm the prediction that abandoning the draft and moving towards an all-volunteer system would lead to a more balanced gender representation in the armed forces.

But to what extent does the CR affect the overall pattern of gender relations in terms of inclusiveness? If the state of play of gender relations in the military is to be explored in a comprehensive way, a more sophisticated measure of gender integration than relative numbers should be provided. Therefore, in a second step of the research, an index of gender inclusiveness was proposed to measure the relative situation of the various countries with regard to gender integration in the armed forces. 
The index was thought to capture quantitative aspects such as levels of representation, but also other dimensions of the integration process concerning the structure of opportunities and power distribution. It included structural variables (overall representation of women in active duty forces, occupational sex segregation and rank distribution) as well as the impact of related policies (existence of segregation practices, presence or absence of formal limitations in occupational and hierarchical

Figure 2: Index of gender inclusiveness in NATO (2000) (0 - Lower integration; 19 - Higher integration)

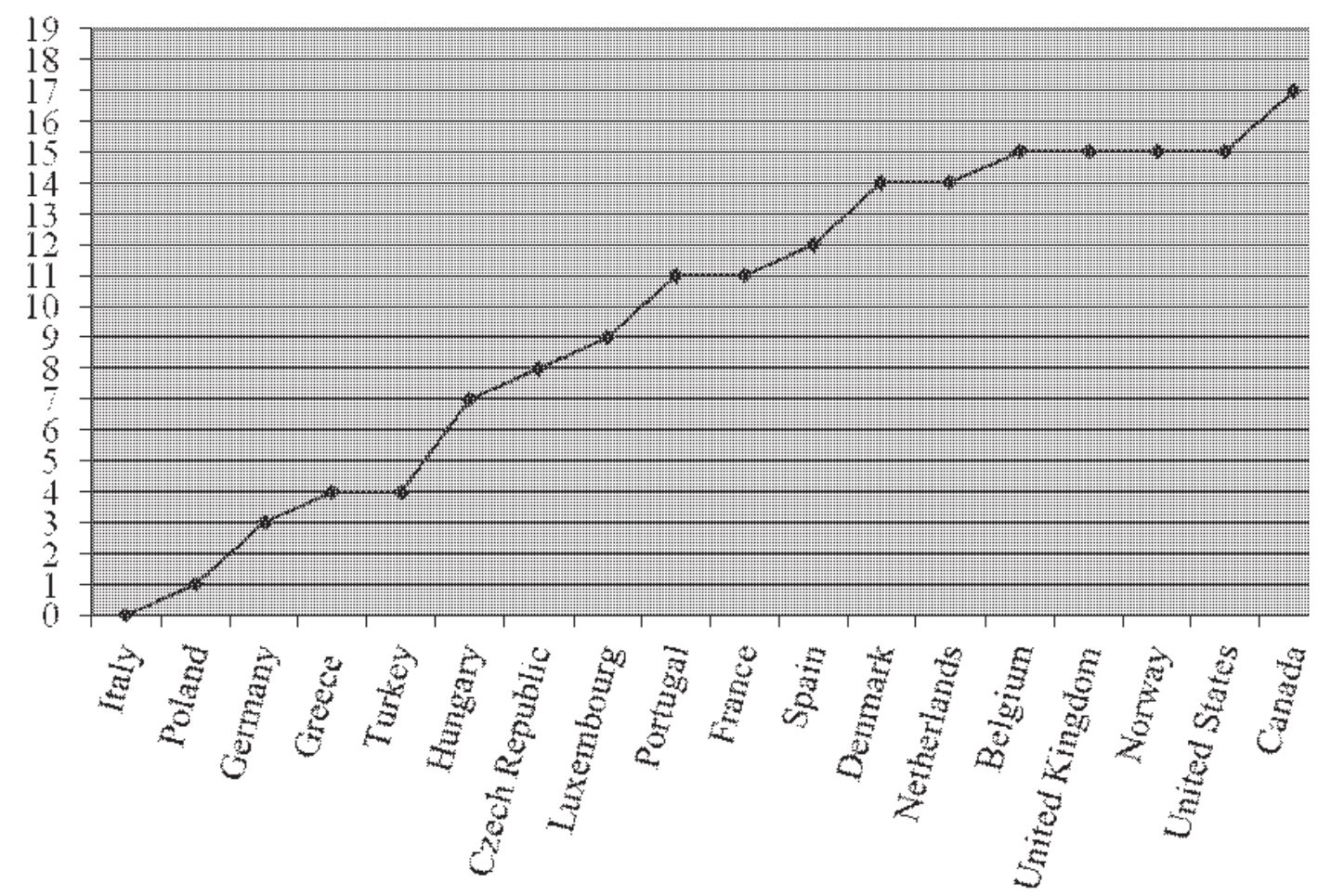

Source: Carreiras, (2006)

terms) and 'quality-of-life' related variables (family programs and sexual harassment and gender-equity monitoring). As such, it provided a more accurate measure for gender integration in the armed forces, than just relative numbers or occupational diversification, even if these were important dimensions of the measure. Results have highlighted great diversity between countries (Figure 2)

This index was then used as a dependent variable in a test of hypotheses aimed at evaluating the effect of social, political and military factors on gender integration. A specific hypothesis was tested regarding the existence of a relation between organizational format and more qualitative indicators such as the diversification of women's military roles. Countries with All-Volunteer Force (AVF) systems of military service were expected to score higher on variables such as the proposed gender inclusiveness index, while countries with higher conscript ratios were expected to show the lower scores in this type of measure. Once again, results pointed to a significant, even if moderate, negative statistical correlation between both variables: the higher the conscript ratio, the lower the level of inclusiveness. ${ }^{3}$

The corresponding scatterplot (Figure 3) displays a visual representation of the countries' relative positions along both dimensions. Despite some deviant cases, those countries with high conscript ratios like Turkey, Greece or Poland had the lowest scores in terms of gender integration, while AVF cases such as the US, UK, Belgium, Canada and the Netherlands showed the best performances of the index.

In any case, since this greater dispersion was not observed in the correlation between the CR and strict quantitative representation, it was considered that the variable 'organizational format' helped to explain variation in relative numbers more than it did in terms of the overall inclusiveness index. This seemed to be supported by other results. For instance, the relation between organizational format (CR) and a partial index of occupational integration - a variable that measured specifically role diversification, revealed a low negative correlation between these variables. ${ }^{4}$

In sum, it was concluded that organizational format was a good predictor of women's representation, but did not seem to influence to the same extent role differentiation, one of the crucial elements in the definition of gender-integration in the armed forces. In the light of this data, the hypothesis was thus raised that other external factors would probably help to better explain the 'quality' of the process (the level of gender integration). Indeed, Carreiras research showed that other variables, namely those related to the social-economic and political structures seemed to have a negligible influence over numerical representation of women in the military but a very significant impact on their global integration. When a measure of gender equality in society at large, including three basic dimensions of empowerment -economic participation

\footnotetext{
$3 \quad(\mathrm{R}=-.683$; Sig. 0.01).

$4 \quad(\mathrm{R}=-.431$; Sig., 0.05)
} 
and decision-making, political participation and decisionmaking and power over economic resources- was tested (GEM), ${ }^{5}$ a very strong relation with the index of gender inclusiveness was detected.

Overall, the results of this study showed that gender inclusiveness was higher in countries more exposed to the democratization of gender relations in society at large and to external political pressures to achieve gender equality in the military. Likewise, gender inclusiveness was higher where the military had opened up to society due to organizational shifts towards professionalization and where gender equality policies had been implemented in the armed forces. Contrarily, and regardless of the moment when women joined the military, in countries where those external influences had not been felt with the same intensity, where the military remained closer to a mass-army format, were women had not reached a 'qualified' position in the social structure, there were lower levels of gender inclusiveness in the military (Carreiras, 2006:200).

\section{Military Organizational Format and Gender Integration Policies: The Challenges Ahead}

Research results show that patterns of gender relations in the military change in the direction of greater inclusiveness due to a complex set of variables, including structural change in military organization, namely in personnel accession policies; but they also stress that global social and political conditions and their impact on policies inside the armed forces may be even more significant than organizational changes. Although associated with greater balance between proportions of men and women, inclusiveness is not a direct consequence of increasing numbers of women. It develops due to simultaneous organizational and societal pressures.

In any case, changing the organizational structure towards allvolunteer forces has cumulative consequences: on the one hand, there is an increased dependency on the labor market to attract qualified personnel for the ranks, which, in turn, requires, on the part of military decision-makers, greater attention to civilian social and cultural dynamics in recruitment efforts; on

5 GEM is a combined index measuring gender inequality. It includes the following indicators: 'seats in parliament held by women', female legislators, senior officials and managers', 'female professional and technical workers' and 'ratio of estimated female to male earned income' (cf. UNDP, 2001: 244-245). It varies between 0 and 1 . the other hand, diversity is an expected outcome, including an increasing representation of women and possibly of other previously underrepresented groups. Managing diversity more than ensuring homogeneity is thus the central challenge for personnel policies in the armed forces. Furthermore, these changes require greater attention to issues of integration, effectiveness or cohesion. This is not because diversity is, in itself, more likely to induce lack of cohesion or effectiveness than social homogeneity. On the contrary, different authors have rightfully pointed out that homogeneous groups are not necessarily more effective than more heterogeneous groups, and that good leadership, technological innovation (e.g. ergonomic studies) or monitoring programs may help produce the necessary adjustments (Lorsch, 1985; Kier, 1999); it is rather because research on the integration of women in the military has shown that some effects are set in motion that might raise concerns about the level of integration of the forces. Since women are usually minorities in these organizations -notwithstanding their growing representation- three effects associated with tokenism (Kanter, 1977) have been frequently been observed: performance pressures due to high visibility, social isolation resulting from the exaggeration of differences by the dominant group (contrast), and finally role-encapsulation, as an effect of gender stereotyping (assimilation).

While some authors have emphasized the importance of institutional policy to overcome these negative effects (Yoder, Adams and Prince, 1983; Rosen et al. 1996), others have stressed the major impact of culture and the limits of formal policies in redressing culturally entrenched stereotypes. According to this later position, acceptance problems happen because of the central role that hegemonic masculinity has played 
in the construction of military identity and also because of its nice fit with another military core value: uniformity. Katzenstein and Reppy have noted that "persistent gender discrimination suggests that there are aspects of military culture that actively promote intolerance. Military culture is at odds with official policy on gender integration because masculinity has traditionally been central to military identity and culture" (Katzenstein and Reppy, 1999: 2). In this view, frequent incidents related to sexual harassment, for instance, should not be understood as a failure to have rules but rather as a result of the clash between a sexist culture and official policies on gender integration. Accounting for the persistence of many of the problems of gender integration in the military is a dominant culture of masculinity more than the lack of rules, the deficient leadership or the absence of adequate policy. In a similar vein, Carreiras $(2006,2010)$ sustained that policies aiming at formal integration may sometimes turn out to work against social integration, and that cultural values regarding masculinity and femininity, as well as those concerning women's social roles, can work as countervailing forces in the process of gender integration in the military, even when all other conditions are favorable. Therefore, policies are seen as a necessary but not sufficient condition to ensure the sustainability of gender integration. However, this does not mean that integration policies should be discarded, but rather that the conditions under which their efficacy varies should be taken into account, considering both external contextual variables (e.g. institutional anchorage; articulation or conflict with policies of other gender regimes) and internal features (flexibility vs. rigidity, stability vs. volatility, coherence, coordination, forms of implementation and control).

Planning, implementing and evaluating integration policies are thus renewed challenges ahead of militaries that change their organizational format towards all-volunteer forces. We might then argue that, with regard to managing gender relations in the armed forces, this new policy focus should be a major consequence of abandoning the draft.

\section{References}

Carreiras, Helena. 2006. Gender and the Military. Women in the armed forces of Western Democracies, London, Routledge.

Carreiras, Helena. 2010. "Gender integration policies in the Armed Forces: a double-hedged sword?" in Caforio, Giuseppe (ed.) Advances in Military Sociology: Essays in honor of Charles C. Moskos, Elsevier.

Haltiner, Karl W. 1998. "Mass Armies in Western Europe." Pp. 38-63 in The European Military in Transition, ed Marie Vlachová. Baden-Baden: Nomos Verlagsgesellschaft.

Harries-Jenkins, Gwinn. 1980. The Role of Women in the European Armed Forces. Hull: University of Hull.

Holm, Jeanne. (1982)1993. Women in the Military: an Unfinished Revolution. Novato, Calif.: Presidio Press.

Iskra, Darlenne, Stephen Trainor, Marcia Leithauser, and Mady W. Segal. 2002. "Women's Participation in Armed Forces
Cross-Nationally: Expanding Segal's Model." Current Sociology 50(5):771-97.

Kanter, Rosabeth M. (1977)1993. Men and Women of the Corporation. New York: Basic Books.

Katzenstein, Mary F. and Judith Reppy, eds. 1999. Beyond Zero Tolerance, Discrimination in Military Culture. Lanham: Rowan \& Littlefield Publishers.

Kier, Elizabeth. 1999. "Discrimination and Military Cohesion: an Organizational Perspective." Pp. 25-52 in Beyond Zero Tolerance. Discrimination in Military Culture, eds Mary F. Katzenstein and Judith Reppy. Lanham: Rowan \& Littlefield.

Kümmel, Gerhard. 2002. "When Boy Meets Girl: The 'Feminization' of the Military. An Introduction Also to Be Read As a Postscript." Current Sociology 50(5):615-39.

Lorsch, J. 1985. "Strategic Myopia: Culture As an Invisible Barrier to Change." Gaining Control of the Corporate Culture, eds Ralph H. Kilmann, Mary J. Saxton, and Roy Serpa. San Francisco: Jossey-Bass.

Moskos, Charles and Frank Wood, eds. 1988. The Military, More Than Just a Job? Washington: Pergamon-Brasseys.

Moskos, Charles, Jay Williams, and David R. Segal, eds. 2000. The PostModern Military . New York: Oxford University Press.

Reynaud, Emmanuel. 1988. Les Femmes, la Violence et l'Armée. Paris: Fondation pour les Études de Defense Nationale.

Rosen, Leora N., Doris B. Durand, Paul D. Bliese, Ronald R. Halverson, Joseph M. Rothberg, and Nancy L. Harrison. 1996. "Cohesion and Readiness in Gender-Integrated Combat Service Support Units: the Impact of Acceptance of Women and Gender Ratio." Armed Forces and Society 22(4):537-53.

Segal, Mady W. 1995. "Women's Military Roles Cross-Nationally - Past, Present and Future." Gender and Society 9(6):757-75.

Simon, Rita J., ed. 2001. Women in the Military. New Brunswick: Transaction Publishers.

UNDP. 2001. Human Development Report 2001. New York: UNDP.

Winslow, Donna and Jason Dunn. 2002. "Women in the Canadian Forces: Between Legal and Social Integration." Current Sociology 50(5):641-67.

Yoder, Janice D., Jerome Adams, and Howard Prince. 1983. "The Price of a Token." Journal of Political and Military Sociology(11):325-37. 